\title{
Leitura e consciência linguística
}

\author{
Reading and linguistic awareness \\ Onici Claro Flôres \\ Universidade de Santa Cruz do Sul, Santa Cruz do Sul, RS, Brasil
}

$\diamond$

\begin{abstract}
Resumo: Neste artigo a leitura é vista como uma atividade cognitiva complexa que envolve necessariamente o desenvolvimento da consciência linguística do leitor iniciante, a começar pela consciência fonológica. Nessa perspectiva, aprender a ler exige, antes de qualquer outra coisa, relacionar a fala ao sistema de escrita, vocalizando a produção do fonema correspondente ao grafema escrito, pois o sistema do Português Brasileiro é alfabético. Aos alfabetizadores, recomenda tanto o estudo do sistema fonológico do PB quanto dos fundamentos biológicos da atividade leitora, tanto para entenderem melhor o princípio alfabético quanto os vínculos entre cérebro, linguagem e fala. Além disso, reitera a importância de contextualização do processo de ensino-aprendizado, situando-o no contexto social e cultural do aprendiz, não desconsiderando, pois, o seu conhecimento prévio.
\end{abstract}

Palavras-chave: Leitura; Consciência linguística; Ensino

\begin{abstract}
This article considers reading as a complex cognitive activity that necessarily involves the development of linguistic awareness of the beginners, starting with the phonological one. In its viewpoint, learning reading demands the establishment of connections between speech and the written system, since the Brazilian written system is alphabetic. Concerning the teaching of reading, it proposes that teachers should take into account the biological foundations of language and the phonological principles of Brazilian Portuguese. In addition, it stresses the importance of contextualizing the process of teaching reading to the learners' social and cultural context, without ignoring their prior knowledge.
\end{abstract}

Keywords: Reading; Linguistic awareness; Teaching

\section{Introdução}

O presente artigo propõe uma concepção não modular do funcionamento mental, entendendo haver interdependência entre cognição e linguagem $(\mathrm{KOCH}$; CUNHA-LIMA, 2007), opondo-se à perspectiva teórica do modularismo estrito. Em sua perspectiva, linguagem e cognição entram em sincronia, para que os indivíduos se comuniquem e também para que aprendam a ler. Ler com eficácia, porém, constitui-se em uma atividade sociocognitiva complexa, demandando outras habilidades além das cognitivas, em sentido estrito.

Em sua perspectiva, para abordar a leitura, é preciso antes se situar a respeito de quais sejam as funções intelectuais da linguagem existentes no cérebro humano. Para tanto se adita que, segundo os estudos existentes na atualidade (PRIMI, 2003), coexistem no cérebro duas funções linguísticas não redutíveis: fala e linguagem. A dissociação embasa-se em pesquisas da psicologia cognitiva, que revisou os testes psicométricos usados para mensurar a inteligência e, a partir do início do séc. $\mathrm{XXI}$, passou a avaliar as diferentes funções cognitivas, em separado. A atual tendência respeita a natureza multidimensional da inteligência, descartando a visão unidimensional que dominou o início do desenvolvimento dos testes psicométricos, ao mesmo tempo reconhecendo a existência do fator g (global) (PRIMI, 2003).

Hoje, linguagem e fala são reconhecidas como duas funções intelectuais distintas, recebendo tratamento diferenciado. Quanto à linguagem, ela corresponde a um sistema de sinais simbólicos utilizados pelos indivíduos para interagir entre si. Entre os indivíduos falantes, por exemplo, esse processamento envolve o desenvolvimento 
dos pensamentos a serem comunicados; a seleção, formulação e ordenação das palavras; a obediência às regras gramaticais da língua considerada e os movimentos psicomotores para produzir a fala. Com os não falantes a mobilização dessa função é um pouco diferente, já que não compreende a emissão da fala, mas de forma geral obedece às mesmas etapas. Em síntese, a função cognitiva linguagem remete à condição biológica de se comunicar através de símbolos, tal como preconizado, por exemplo, por Saussure (2008), que a define como uma habilidade humana natural. Essa função, ainda que se manifeste de modos distintos, é comum a falantes e a não falantes, como é o caso dos surdos, que se comunicam através da língua de sinais.

No que respeita à fala, há que acrescentar que não se confunde com a função linguagem, inclusive, por ser apreensível através da via auditiva, sendo abordada em pesquisas sobre a aquisição da linguagem por teóricos das várias tendências, como psicolinguistas chomskianos, sociocognitivistas, etc. (QUADROS, 2008; BORGES; SALOMÃO, 2003). Desse modo, a partir do estabelecimento da distinção entre as funções cognitivas linguagem e fala, por vezes omitida, inicia-se o presente artigo enfatizando-a, já que ambas implicam a condição biológica de se comunicar através de símbolos, mas não se recobrem, integralmente.

O foco de interesse do presente artigo é, no entanto, a leitura, que é uma atividade linguística ao mesmo tempo distinta da fala, porque exercida com os olhos, porém dela não se dissociando totalmente (CANSINO, 2002). Vale acrescentar, ainda, que a base física da leitura só foi atestada de modo empírico (em cérebros ilesos), com a publicação das pesquisas de Dehaene (2007), que utilizou técnicas de imageamento cerebral. Esse autor acrescenta, ainda, que a aprendizagem da leitura alterou as redes corticais da visão e da linguagem verbal, porque aprender a ler "consiste em acessar, através da visão, as áreas da linguagem falada [...]" (DEHAENE, 2013, p. 148).

Evidencia-se, dessa forma, que ler exigiu uma adaptação do cérebro, que não evoluiu geneticamente para isso. Essa adaptação, inclusive, demandou reciclagem neuronal, ou seja, um reajuste dos neurônios da área transmodal destinada, geneticamente, à visão. Foi esse reajuste que possibilitou que o cérebro humano passasse a desempenhar a tarefa de ler a escrita (DEHAENE, 2007, 2010, 2012). E o autor prossegue sua argumentação, acrescentando que no cérebro humano, apenas uma região destina-se precípua e exclusivamente à leitura, de vez que:

[...] é a única a ser ativada exclusivamente para a leitura das palavras escritas e não para as palavras faladas, sem, contudo, pertencer às regiões visuais de baixo nível que se ativam à vista de estímulos simples, como o tabuleiro de xadrez. Ela se situa, pois, no cruzamento entre a análise visual e o resto do sistema linguístico (DEHAENE, 2012, p. 83-84).

\section{As inter-relações entre fala, leitura e escrita}

Por outro lado, em sentido estrito, o que se lê é a escrita, e a escrita do português é alfabética. Os sistemas alfabéticos, contudo, diferem bastante entre si, pois alguns são mais transparentes e outros menos. O sistema do português é considerado de média opacidade (PINTO, 1998), em vista disso é bem possível que parte dos dialetos sociais usados pela população brasileira possa dificultar o aprendizado da leitura, sobretudo, entre aprendizes de determinadas regiões e grupos sociais, uma vez que seu modo de falar usual pode criar empecilhos à abordagem do texto escrito.

Essa possibilidade fez com que pesquisadores da área da linguística (CAGLIARI, 1999) passassem a analisar os testes padronizados utilizados pelos psicólogos cognitivos para avaliar a habilidade leitora de crianças. A análise feita levou a que esses estudiosos se opusessem à ideia de que as dificuldades de aprendizagem de leitura detectadas entre os iniciantes fossem avaliadas com base na escrita. A ponderação de Cagliari é referente à necessidade de cautela no diagnóstico, pois se a criança é testada em leitura, pelo que escreve, o diagnóstico de dislexia a que professores e pais tendem a recorrer, após a aplicação dos testes, é precipitado. Há que convir que a dislexia é uma disfunção cerebral.

Assim, antes de diagnosticar uma criança como sendo disléxica através de um teste padronizado, além do mais baseado na escrita (ortografia), faz-se necessário ponderar a respeito de uma série de fatores, dentre eles a diversidade dialetal dos aprendizes e do professor alfabetizador. A diversidade de falares (regionais e sociais) do Brasil é bem conhecida, sendo que, segundo afirma Abaurre (2013, p. 239): "Em um país de grande extensão territorial, história de ocupação complexa e diferenciada, não é simples delimitar áreas dialetais, pois não há uma coincidência de áreas nem uma distribuição homogênea dos fenômenos pelas áreas, tampouco, do ponto de vista sincrônico, evidências inequívocas que expliquem a ocorrência das variantes".

É inegável, por outro lado, que o desenvolvimento das habilidades básicas para a leitura tem grande impacto social, concentrando a atenção e aumentando a expectativa de pais, professores, administradores, políticos e, de modo geral, de toda a população a respeito do êxito nesse aprendizado. A expectativa é enorme. Entretanto, é bom considerar que a aprendizagem da leitura pode representar 
um desafio enorme para parte dos iniciantes, que podem manifestar diferentes tipos e graus de dificuldade ao longo do processo. $\mathrm{O}$ alerta sobre a não trivialidade do aprender a ler e sobre os possíveis percalços decorrentes de uma avaliação pouco confiável refere-se, principalmente, a testes que avaliam leitura e ortografia, em conjunto, sendo esse tipo de testagem a que se opõe Cagliari (1999). Avaliar o aprendizado da leitura, diz ele, tem de testar a leitura, havendo, todavia, testagens que avaliam, sobretudo, se a criança sabe escrever de modo convencional. Nessas testagens, os avaliadores solicitam que a criança escreva o que solicitam, baseando-se na escrita para comprovar o seu conhecimento de leitura e escrita.

Há que reiterar, porém, que leitura é leitura e escrita é escrita, embora essas duas habilidades linguísticas mantenham entre si relações de reciprocidade e de interdependência. Por isso, os estudos comparativos sobre a complexidade ortográfica de diferentes línguas alfabéticas são produtivos, pois esclarecem a respeito do grau de transparência/opacidade da escrita, mas isso não justifica nem implica aceitar a avaliação da leitura apenas através de um exercício de escrita, de vez que, se a opacidade do sistema de escrita pode influenciar sua aprendizagem, facilitando-a ou dificultando-a, daí não se conclui que se deva testar unicamente a escrita para saber se a criança sabe ler.

Uma pesquisa de Veloso (2005) fez um levantamento a respeito das línguas alfabéticas que já investigaram o tema opacidade/transparência, comparativamente. Tais estudos, diz o autor, apontam quais sejam os aspectos fundamentais das diferenças entre as línguas alfabéticas. Com base nessas distinções pode-se concluir que as diferenças mais significativas entre os sistemas alfabéticos são de dois tipos: 1) complexidade silábica e 2) ortografia. Dessa constatação depreende-se, também, que com relação à leitura, em especial, as estruturas silábicas afetariam a decodificação, enquanto que a profundidade ortográfica afetaria a leitura de palavras desconhecidas e de pseudopalavras.

Com base nesse estudo de Veloso, em especial, comprova-se ser indispensável, então, avaliar a leitura com testes que deem destaque à decodificação e à inferenciação e, além disso, como sugere Cagliari (1999), aprofundar as pesquisas sobre a escrita dos iniciantes e suas alterações ortográficas em português brasileiro, com a finalidade de melhor compreender como as crianças estão construindo seu conhecimento da língua, ao invés de, simplesmente, classificar os erros como ocorrências negativas que não contribuem em nada para o aprendizado. Como afirma Cagliari (1999), os erros ortográficos fazem parte da aprendizagem do ler e do escrever, sobretudo, do escrever, podendo revelar como as crianças estão relacionando o modo como falam com a língua escrita.
De todo modo, não se pode descartar a possibilidade de algumas crianças poderem eventualmente apresentar alguma disfunção cognitiva, exibindo diversidade e frequência de problemas relativos à leitura, bem como alterações de escrita peculiares e persistentes. Tais dificuldades revelam não somente má qualidade de ensino, como alguns mais apressados costumam antecipar, mas também possíveis problemas ou limitações, ou seja, distúrbios de aprendizagem, entre eles, dislexia de desenvolvimento. Nesse caso, o mais acertado é discutir o problema com os pais, dar aulas de reforço e, por fim, encaminhar a criança para atendimento especializado. $\mathrm{O}$ fato é que a leitura e a escrita envolvem o uso de estratégias fonológicas e ortográficas, e algumas crianças podem ter grandes dificuldades com os aspectos fonológicos, enquanto outras podem ter limitações quanto à ortografia. Em tese, a influência genética mais forte se relacionaria às dificuldades fonológicas, enquanto que as dificuldades de natureza ortográfica teriam maior influência ambiental, tendo em vista o seu caráter convencional. Essa última possibilidade deve ser um sinal de alerta para os alfabetizadores, porque muitas das crianças que ingressam na escola têm pouca ou nenhuma familiaridade com o texto escrito, e isso só pode ser sanado com muita leitura e com muito pareamento entre grafemas e fonemas.

Grabe (2009) pesquisou vários sistemas de escrita, tanto alfabéticos quanto não alfabéticos, e sustenta que nas escritas alfabéticas a leitura estabelece estreitos vínculos com a fonologia, de acordo com o sistema de cada língua. Mas os sistemas alfabéticos também se relacionam aos aspectos morfológicos codificados na ortografia. Em adendo, há também de pensar na etimologia (origem da palavra) que por vezes é preservada na escrita e pode dificultar o aprendizado de leitura e/ou escrita, como se pode constatar através da citação de Veloso:

No caso do português, p. ex., é graças unicamente ao critério etimológico que a representação gráfica de certas palavras admite a letra $\mathrm{h}$ em posição inicial, em vocábulos como "homem" ou "hoje", em que tal símbolo gráfico é desprovido de qualquer relação com o plano fonéticofonológico da língua no seu estádio actual (VELOSO, 2005, p. 6).

\section{A importância da Morfologia para o aprendizado da leitura do texto escrito}

Em português brasileiro, além da preocupação com o desenvolvimento da consciência fonológica, ou seja, com o estabelecimento da inter-relação grafema/fonema, temse de estar atento aos elementos morfológicos codificados na escrita, segundo o recomendou Grabe (2009). Alguns desses elementos não são registrados na fala distensa, nem mesmo na fala geral, mas estão presentes na escrita 
e na fala formal. Em função disso, retoma-se o conceito de morfema, unidade linguística que estrutura a palavra e que possui significado próprio, a qual é definida por Laroca (2005), como uma forma mínima recorrente que mantém o mesmo traço semântico em todas as estruturas em que ocorre.

Os morfemas do português podem ser flexionais, derivacionais, classificatórios e relacionais, sendo que para o presente artigo é relevante conceituar os dois primeiros tipos referidos. Os morfemas flexionais são assim denominados pois flexionam ou alteram os morfemas lexicais (radicais) para se adequarem à expressão das categorias gramaticais, segundo a classe de palavra que passam a constituir. Se a palavra for um nome, a flexão pode ser de gênero e número, ao passo que os verbos flexionam-se de acordo com o modo, o tempo, o número e a pessoa. Há que ressaltar, também, que os morfemas flexionais obedecem a uma sistematização obrigatória, de acordo com a sua flexão (SILVA; KOCH, 1999). Já os morfemas derivacionais são responsáveis pela criação de novas palavras, derivadas de palavras primitivas a partir de um morfema lexical (primitivo), não sendo eles tão regulares e coerentes como os flexionais (SILVA; KOCH, 1999). Dessa forma, a derivação implica a criação de uma palavra nova, que pode pertencer a uma categoria gramatical diferente daquela da palavra primitiva (ex.: trabalhar, trabalhador).

A breve revisão feita dimensiona a complexidade da morfologia do português. Dela se infere que a multiplicidade de aspectos morfossintáticos presente na escrita e, em ocasiões determinadas, também na fala (formal), pode representar dificuldades aos leitores iniciantes das camadas populares, pois, de modo geral, esses falantes não utilizam as mesmas marcas morfológicas da escrita de nomes e de verbos, em nenhuma circunstância - formal ou informal - dos usos linguísticos orais ou escritos que empregam, usualmente, para se expressar. Para exemplificar o que se afirma, vãose registrar alguns exemplos: 'nós vai' por 'nós vamos'; us pé por 'os pés'; 'us omi' por 'os homens'; 'as galinha ponhá ovu' por 'as galinhas põem ovos', 'qué que eu busco o livro?' por 'quer que eu busque o livro?' e assim por diante. O problema desses falantes parece ser o da falta de alternativa, pois a maioria deles não teve nem tem contato com as outras formas paradigmáticas da língua escrita e isso acaba por imobilizá-los, expressivamente, complicando ainda mais o seu aprendizado da leitura. Em suma, esses falantes não conseguem mudar o registro em situações em que isso se faz necessário.

Assim, no processo interativo usual das pessoas pouco escolarizadas, fala e escrita acabam ficando muito distintas formalmente e essa circunstância dificulta o aprender a ler. Ou por outra, apesar de leitura e escrita serem processos que mantêm fortes laços de interdependência entre si, a relação da escrita com a fala pode se distanciar bastante. Em vista disso, se existe reciprocidade, interdependência, não existe, todavia, identidade, pois aprender a ler não pode ser confundido com falar nem com aprender a escrever, visto que essas três habilidades linguísticas são diferentes e cada uma delas tem de ser avaliada de modo distinto.

Marec-Breton e Gombert (2004) destacaram que a escrita é composta de dois princípios: o fonográfico, que se relaciona ao vínculo existente entre as letras (grafemas) e os sons (fonemas) que compõem as palavras e o semiográfico, que diz respeito à estruturação das palavras a partir dos seus morfemas. O princípio fonográfico relaciona-se à consciência fonológica e o semiográfico à consciência morfológica, temas a serem abordados nas próximas seções.

Concluindo a presente seção, reitera-se que ler exige a apreensão do princípio alfabético, não sendo algo natural como falar e escutar. Em função disso, cabe ao professor, nos grupos comunitários em que a família não inicia a criança em leitura, introduzir as crianças no mundo da escrita, tomando ciência, ainda, das atividades culturais da comunidade em que vai lecionar, para poder fazer um trabalho que respeite as diferenças culturais e as valorize, ao mesmo tempo mostrando as diferenças entre falar, ler e escrever, sem desqualificar o modo de se expressar dos iniciantes.

\section{Consciência Fonológica e Morfológica}

Por vezes, pais e familiares enganam-se a respeito do conhecimento de uma dada criança, por ter aprendido a ler, segundo eles, precocemente. Pode acontecer, é claro. Mas é aconselhável observar se a criança não decorou o livro. Muitas crianças costumam aprender de cor um considerável número de palavras e parecem saber ler, quando, na verdade, memorizaram as palavras, sem saber lidar com os elementos que as constituem. Em vista disso, o teste mais confiável para verificar se uma criança está, de fato, lendo, é solicitar que leia palavras desconhecidas ou pseudopalavras. Sem isso sempre é possível algum engano, ainda mais quando os pais estão orgulhosos, muito orgulhosos do feito da criança. $\mathrm{O}$ iniciante estará lendo, mesmo, a partir do momento em que conseguir estabelecer relações entre as palavras e suas representações, ao estabelecer a correspondência entre grafema(s) e fonema(s). Para fazer isso ela necessita "reconhecer, oralmente, no interior das palavras, as unidades linguísticas sonoras que são os fonemas" (GOMBERT, 2003, p. 25).

Daí se depreende que a consciência fonológica é uma habilidade extremamente importante para a aprendizagem 
da leitura nas línguas alfabéticas. Nessas línguas, o processo de leitura envolve uma série de habilidades, mas duas delas são essenciais e se complementam: a reconstituição falada das palavras escritas e a compreensão do que é reconhecido. Reconhecer uma palavra envolve, então, extrair a pronúncia e o significado de uma dada palavra com base nos sinais gráficos que a representam. Esse é o processo mais básico e específico do ato de ler e implica a conversão de letras (grafemas) em sons linguísticos (fonemas) que façam sentido para o leitor.

Para escrever, por outro lado, o aprendiz precisa: 1) transcrever os sons de uma palavra para a escrita, ou seja, fazer a conversão dos fonemas nos seus sinais gráficos correspondentes (transformar fonemas em grafemas); e 2) redigir um texto respeitando padrões de gêneros, regras gramaticais e ortográficas (MELO, 2006). Tais ponderações confirmam a importância do princípio fonográfico e, consequentemente, da consciência fonológica para a aprendizagem da leitura e da escrita. Essa conclusão apoia-se na constatação de que algumas crianças parecem não ter consciência de que as palavras são formadas por segmentos de sons, os fonemas. Elas têm uma visão mais global da escrita e querem entender o significado, não atentando para a forma daquilo que está escrito (BRYANT; BRADLEY, 1987). Com a experiência e maior contato com textos escritos, a criança passa a prestar a atenção em detalhes antes ignorados, de vez que: "A consciência fonológica requer que a criança ignore o significado e preste atenção à estrutura da palavra" (GOUGH; LARSON, 1995, p. 15). Assim, quando a criança está aprendendo a ler, ela direciona sua atenção aos sons que formam as palavras e isto acontece, provavelmente, porque a educação formal a orienta no sentido de identificar esses sons para fazer a leitura (BRYANT; BRADLEY, 1987).

Anthony e Francis (2005) sugerem que outros elementos, além dos fonemas, desempenham um importante papel no desenvolvimento da consciência fonológica, entre eles a experiência da criança com a linguagem falada e com os textos escritos (leitura compartilhada) (MORAIS, 2013). Com base nisso, considera-se que a consciência fonológica é um fator decisivo, porém não o único a ser levado em conta no que diz respeito à aprendizagem leitora de línguas alfabéticas (GOUGH; LARSON, 1995).

De acordo com Santos e Maluf (2004), resultados de testes na área da leitura e da soletração apontam, de modo geral, para a importância decisiva do desenvolvimento da consciência fonológica. Isso não significa, porém, que ela seja o único fator atuante no desenvolvimento da leitura e da soletração, já que para dominar a escrita alfabética a criança precisa não apenas se deter na análise dos sons linguísticos (fonemas) que compõem as palavras, mas ainda refletir sobre o significado destas mesmas palavras. Menciona-se, em vista disso, o processo de soletração que implica decifrar, ou seja, relacionar os fonemas às letras e, após, separar as letras de cada palavra, aglutinando-as em sílabas, para fazer a leitura. Ao separar as letras da palavra, estruturando-as em sílabas, para então fazer a leitura da palavra, em sua totalidade, as crianças aprendem a ler soletrando; essa leitura é vagarosa, mas muito comum e útil no início do processo, sendo exercitada, de modo usual, pelos professores alfabetizadores. Disso decorre que os termos 'escrita' e 'soletração', bem como a subsequente reflexão sobre o significado das palavras envolvem outra habilidade metalinguística: a consciência morfológica, que também importa aqui considerar (MELO, 2006).

Segundo Carlisle (1995), a consciência morfológica consiste em refletir sobre as partes constituintes da palavra e em manipular, intencionalmente, a sua estrutura morfêmica. Daí decorre que a consciência morfológica relaciona-se à manipulação de bases (radicais) e afixos (prefixos e sufixos), sejam eles flexionais ou derivacionais. Diversas pesquisas indicam que a consciência morfológica contribui para a aprendizagem da leitura e da escrita em vários sistemas de escrita alfabética (CARLISLE, 1995; DEACON; BRYANT, 2005; NUNES; BRYANT, 2006) como também na leitura de palavras individuais, na compreensão de textos e na leitura de pseudopalavras (DEACON; KIRBY, 2004).

De acordo com Nunes e Bryant (2006), os morfemas são de grande importância no processo de aprendizagem da leitura e da escrita. Segundo esses autores, é através da reflexão a respeito deles que a criança pode encontrar maior facilidade em apreender o significado de novas palavras, assim como ler e escrever palavras que desconheça. Frente a uma palavra nova, torna-se mais fácil seu entendimento, se o leitor perceber que a palavra é formada pela combinação de morfemas, cada um com seu significado próprio. Lehtonen e Bryant (2005) acrescentam que a morfologia pode auxiliar na escolha da grafia correta de um morfema que não corresponda às regras de correspondência entre letras e sons.

Mota (2009) acrescenta que nem todos os morfemas são igualmente considerados pelas crianças, no início do aprendizado. Por exemplo, Deacon e Bryant (2005), investigando a escrita de crianças de cinco a oito anos, mostraram que as crianças escreveram melhor as palavras flexionadas do que as derivadas. Assim, com fundamento nas pesquisas citadas, conclui-se que a consciência morfológica é um fator importante para as pesquisas sobre leitura inicial, ainda que o sistema do português seja medianamente transparente. 


\section{Por que a preocupação com a opacidade ou transparência dos sistemas de escrita?}

As línguas alfabéticas (português, francês, espanhol, finlandês, inglês, alemão etc.) utilizam o alfabeto como fundamento de sua escrita. De imediato surge a indagação: Será que por serem alfabéticas essas línguas são parecidas? Um pequeno inventário de quais sejam as línguas alfabéticas já deixa claro que, apesar de sua escrita se embasar no alfabeto, as línguas alfabéticas são bastante distintas entre si. Prossegue a dúvida: Onde, então, está a diferença, se não nos elementos gráficos usados? A resposta é que a diferença reside no modo de falar de cada comunidade linguística. Esse modo de falar se distingue do modo das demais em maior ou menor medida. Considerem-se, por exemplo, as diferenças de fala existentes entre o espanhol, o português, o inglês, o alemão, o francês, o italiano; em seguida, considerem-se suas escritas. A comparação permite constatar que o alfabeto é, na verdade, um inventário das letras usadas numa dada língua - símbolos gráficos da escrita - cada qual representando um fonema da língua falada naquela comunidade linguística. Dessa forma, parece mais fácil explicar por que o alfabeto se relaciona com cada língua de forma distinta. Ele se embasa na língua falada pelo grupo.

Em um alfabeto fonológico ideal, fonemas e letras (grafemas) se corresponderiam tanto na leitura quanto na escrita: o leitor poderia predizer a pronúncia da palavra de acordo com a escrita, e o redator poderia predizer a escrita de acordo com a pronúncia. $\mathrm{O}$ que raramente acontece. Cada língua possui regras gerais que governam a associação entre letras (grafemas) e fonemas (princípios fonológicos), mas, dependendo da língua, essas regras podem ou não ser consistentemente seguidas.

Alfabetos perfeitamente fonológicos são de fácil aprendizado e uso, e as línguas que os possuem, por exemplo, o finlandês (AARON, 1989), têm menos barreiras à alfabetização do que línguas - como o inglês - que têm um sistema bastante irregular. As dificuldades aumentam, caso se considere que as línguas faladas, em geral, se desenvolveram de maneira independente de seus sistemas de escrita. Na maioria dos casos já investigados, os sistemas de escrita foram emprestados de línguas com estruturas bastante diferentes daquelas da língua falada (o português originou-se do latim, sendo uma das línguas neolatinas), existindo ainda grande variabilidade no grau em que as letras do alfabeto correspondem aos fonemas de uma língua para outra, e até mesmo dentro de uma mesma língua.

Em vista disso, o aprendizado da leitura nas línguas alfabéticas implica, em primeiro lugar, que o iniciante aprenda a inter-relacionar letra (grafema)/fonema, ou seja, que transforme signos escritos em signos orais, fazendo uso da rota fonológica (auditiva) ao transformar letras (grafemas) em fonemas. A primeira dificuldade a ser enfrentada pelo aprendiz é que as letras (grafemas) e os sons (fonemas) são entidades que não significam nada, são abstrações.

De outra parte, nos sistemas alfabéticos em que a relação letra (grafema)/fonema é instável, variando muito, os iniciantes têm mais dificuldade de aprendizagem de leitura/escrita. Nesse caso, os sistemas são chamados de opacos. O inglês é um desses sistemas. Já nos sistemas em que as relações são mais consistentes em relação à combinatória letra (grafema)/fonema, o aprendizado costuma fluir com mais facilidade, sendo esses sistemas chamados de transparentes. Alguns autores, inclusive, consideram existir uma oposição graduável entre os sistemas, conforme sejam mais ou menos opacos e/ou transparentes. (AARON, 1989; KORKEAMÄKI, 1997).

Com já comentado, Veloso (2005) fez um levantamento das pesquisas realizadas a respeito dos sistemas de escrita alfabéticos de diversas línguas, como se pode comprovar no Quadro 1, adiante. Nesse quadro, constam estudos realizados a respeito do português de Portugal e de outras línguas alfabéticas como o alemão, o castelhano, o finlandês, o grego, o holandês, o polaco, o italiano, o servo-croata, o turco, o francês e o inglês. O estudo do português de Portugal foi feito comparativamente com os sistemas do francês e do inglês. Tais estudos foram realizados por Pinto, e dentre eles destaca-se o trabalho de 1998. Essa autora concluiu que o português é um sistema de escrita de média transparência, com um grau de consistência bastante regular no princípio alfabético. Quanto ao português brasileiro, não se conhece nenhum estudo similar. Há, entretanto, dois estudos de ScliarCabral (SCLIAR-CABRAL, 2003a, 2003b) que enfocam o sistema fonológico do português brasileiro e explicitam seu funcionamento, os quais são dirigidos, em especial, a professores alfabetizadores.

Assim, segundo o grau de transparência, o sistema de escrita do português brasileiro é, relativamente, transparente, havendo poucos casos em que as correspondências letra (grafema)/fonema não são mantidas; daí se pode concluir que as crianças brasileiras deveriam ter facilidade para aprender a ler, porque, segundo esse critério, o PB é um sistema que não apresenta muitas dificuldades para os iniciantes.

A relativa transparência do sistema alfabético do português pode beneficiar os iniciantes familiarizados com a escrita. $\mathrm{O}$ caso é que se está discutindo, exatamente, as possíveis dificuldades daqueles iniciantes pouco familiarizados. Estes, na certa, vão levar mais tempo para ler do que aqueles acostumados a ouvir histórias; a 
Quadro 1. Línguas com sistemas de escrita foneticamente transparentes e línguas com sistemas de escrita fonemicamente opacos.

\begin{tabular}{|c|c|c|}
\hline & $\begin{array}{l}\text { Línguas com sistemas de escrita } \\
\text { fonemicamente transparentes }\end{array}$ & $\begin{array}{l}\text { Línguas com sistemas de escrita } \\
\text { fonemicamente opacos }\end{array}$ \\
\hline $\begin{array}{l}\text { Aspectos linguísticos privilegiados } \\
\text { pela ortografia canónica }\end{array}$ & $\begin{array}{l}\text { Aspectos segmentais (um segmento fonológico } \\
\text { corresponde a um símbolo gráfico e vice-versa) }\end{array}$ & $\begin{array}{l}\text { - Relações morfofonológicas abstractas; } \\
\text { - Etimologia }\end{array}$ \\
\hline $\begin{array}{l}\text { Aspectos linguísticos secundarizados } \\
\text { pela ortografia canónica }\end{array}$ & $\begin{array}{l}\text { - Relações morfofonológicos abstractas; } \\
\text { - Etimologia }\end{array}$ & $\begin{array}{l}\text { Aspectos segmentais (um segmento fonológico } \\
\text { corresponde a um símbolo gráfico e vice-versa) }\end{array}$ \\
\hline Aprendizagem & Mais fácil, mais rápida & Mais difícil, mais lenta \\
\hline Exemplos de línguas & 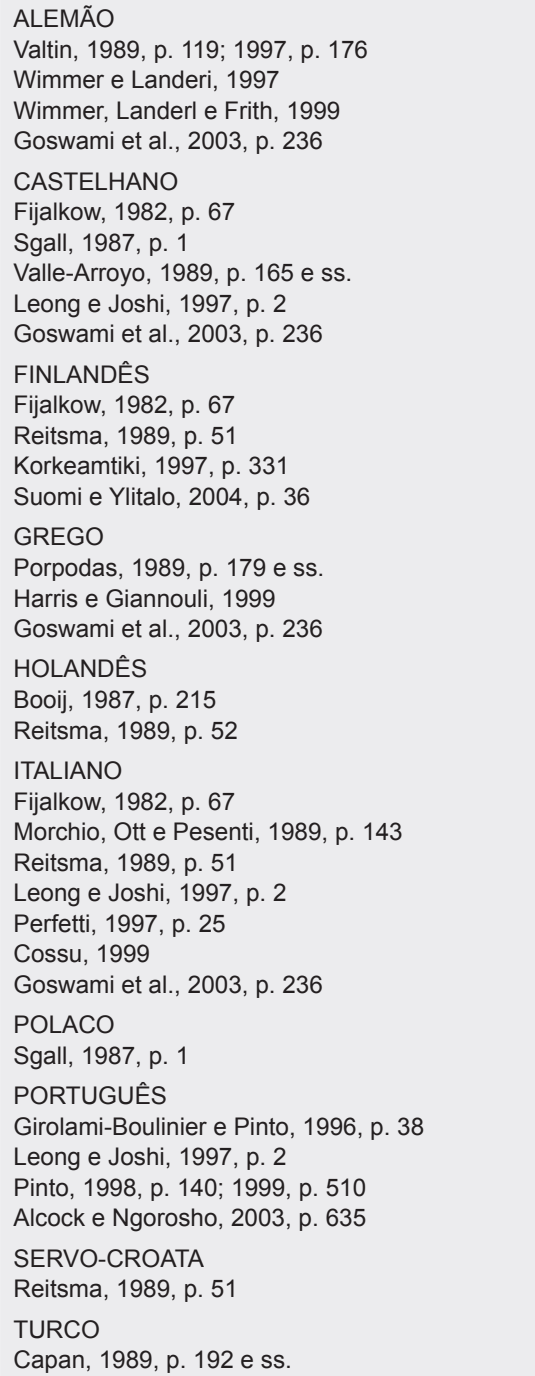 & $\begin{array}{l}\text { FRANCÊS } \\
\text { Fijalkow, 1982, p. } 67 \\
\text { Sgall, 1987, p. } 1 \\
\text { Klees, 1989, p. } 137 \\
\text { Sprenger-Charolles, Siegel e Béchennec, 1997, p. } 339 \\
\text { INGLÊS } \\
\text { Fijalkow, 1982, p. } 67 \\
\text { Sgall, 1987, p. } 1 \\
\text { Snowling, 1989, p. } 1 \\
\text { Luelsdorff, 1991, p. } 1 \\
\text { Leong e Joshi, 1997, p. } 3 \\
\text { Perfetti, 1997, p. } 25 \\
\text { Pinto, 1998, p. } 140 \\
\text { Alcock e Ngorosho, 2003, p. } 635 \\
\text { Goswami et al., 2003, p. } 236\end{array}$ \\
\hline
\end{tabular}

Fonte: Veloso (2005, p. 10)

manusear livros, jornais e revistas; a fazer relatos; a cantar e a declamar; enfim, para aqueles que têm oportunidade de pensar e organizar o que dizer, a falar e a se fazer ouvir. É claro, para esses alunos, ler pode parecer fácil. Mas a atividade cognitiva é exigente, para todo aprendiz.

Além disso, sabe-se não ser incomum que alguns iniciantes necessitem de mais tempo para automatizar o processo de mediação fonológica, não adquirindo fluência leitora na velocidade de seus pares. Assim, a variável tempo é importante no aprendizado de leitura e de escrita, porque, entre outros fatores dificultadores, caso a variante de fala usada pela criança em sua comunidade seja diferente da fala geral e, mais ainda, do sistema de escrita, essa criança terá de despender esforços adicionais no processamento cognitivo. O aprendizado requerido demanda que o aprendiz não só descubra a inter-relação letra (grafema)/fonema, como também mecanize o processo de conversão, uma vez que o seu entendimento terá de se manifestar de modo eficiente, no exato momento da leitura, exigindo rapidez. 
Na verdade, não se pode ignorar que ler parece fácil porque já se aprendeu a ler há muito tempo atrás. Além do mais, é bom lembrar que crianças pouco habituadas com o texto escrito, bem como com suas funções sociais diversas, na certa, vão necessitar de mais tempo e exercício para automatizar o processo de decodificação e de codificação. Os ritmos de aprendizagem são diversos e as experiências culturais heterogêneas. Em suma, embora a rota fonológica, que é indireta e exige o pareamento grafema-fonema, seja utilizada por todos os leitores inexperientes, o ritmo em que o processo é automatizado, de modo geral, pode ser bastante diferente e alguns alunos podem não acompanhar o ritmo de aprendizagem dos demais. Eles precisam de mais exercício do que os colegas, embora não, necessariamente, apresentem algum problema de aprendizagem sério.

\section{Considerações finais}

Para concluir, reitera-se que a aquisição da língua (fala) é natural e inconsciente, ou seja, o cérebro humano já nasce programado geneticamente para fazer isso. Porém, a escrita é um objeto cultural e cada tipo de ortografia tem profundas raízes em sua cultura de base, sendo as diferenças ortográficas comprováveis, de imediato, mesmo que se considerem, com exclusividade, as escritas alfabéticas.

Dessa forma, ainda que a leitura faça parte dos estudos da linguagem, não é adquirida incidentalmente. Se a fala e a sua audição funcionam de modo automático, sem reflexão consciente, o mesmo não acontece com a leitura, que exige consciência linguística em vários níveis (PINTO, 1994). Na verdade, a atividade leitora embasa-se no entendimento do modo como funciona o sistema ortográfico usado numa dada comunidade. Ao que se acrescenta que a linguagem humana tem um fundamento interno (psicológico), mas também tem uma base contextual, social, cultural. Ou seja, aprende-se a ler na escola que se frequenta, com a professora que ministra aulas naquele local, vivendo na comunidade em que se vive, participando da vida daquela comunidade e valorizando ou não a leitura de acordo com as crenças e os valores da comunidade em que se vive.

Enfim, quando se trata da leitura e seu aprendizado, não é possível confiná-la ao cérebro do indivíduo, como uma habilidade individual, estritamente, intelectual, uma vez que a natureza dessa atividade sociocognitiva envolve o psicológico, é evidente, mas também o social, o contextual. Em famílias de leitores, a facilidade é, em geral, maior, todavia aprender a ler é um direito de todos, sendo necessário fazer todo o esforço possível para franquear o acesso à leitura a todos os iniciantes, de todos os grupos sociais.

\section{Referências}

AARON, P. G. Orthographic Systems and Developmental Dyslexia: A Reformulation of the Syndrome. In: AARON, P. G.; JOSHI, M. (Ed.). Reading and Writing Disorders in Different Orthografic Systems. Dordrecht/Boston/London: Kluwer Academic Publishers/NATO Scientific Affairs, Affairs, 1989.

ABAURRE, M. B. M. (Org.). A construção fonológica da palavra. São Paulo: Contexto, 2013.

ANTHONY, J. L.; FRANCIS, D. J. Development of phonological awareness. Current Directions in Psychological Science, v. 14, n. 5, p. 255-259, 2005.

BORGES, L. C.; SALOMÃO, N. M. R. Aquisição da linguagem: considerações da perspectiva da interação social. Psicologia: Reflexão e Crítica, v. 16, n. 2, p. 327-336, 2003.

BRYANT, P.; BRADLEY, L. Problemas de leitura na criança. Porto Alegre: Artes Médicas, 1987.

CAGLIARI, L. C. ALFABETIZANDO sem o BA-BÉ-BI-BÓ-BU. São Paulo: Scipione, 1999.

CANSINO, E. La mirada auditiva. In: ALONSO. F. et al. Hablemos de leer. Madrid: ANAYA, 2002. p. 31-43.

CARLISLE, J. F. Morphological awareness and early reading achievement. In: FELDMAN, L. B. (Ed.). Morphological aspects of language processing. 1995. p. 189-209.

DEACON, S.; BRYANT, P. What young children do and do not know about the spelling of inflections and derivations. Developmental Science, v. 8, n. 6, p. 583-594, 2005.

DEACON, S. R.; KIRBY, J. Morphological awareness: Just "more phonological"? The roles of morphological and phonological awareness in reading development. Applied Psycholinguistics, v. 25, n. 2, p. 223-238, 2004.

DEHAENE, S. Les Neurones de la Lecture. Paris: Odile Jacob, 2007.

DEHAENE, S. Os neurônios da leitura - como a ciência explica a nossa capacidade de ler. Trad. Leonor Scliar-Cabral. Porto Alegre: Penso, 2012.

DEHAENE, S. A aprendizagem da leitura modifica as redes corticais da visão e da linguagem verbal. Letras de Hoje, Porto Alegre, v. 48. n. 1, p. 148-152, jan.-mar. 2013.

DEHAENE, S. et al. How learning to read changes the cortical networks for vision and language. Science, v. 330, p. 1359 1364, 2010.

GOMBERT, J. E. Atividades metalinguísticas e aprendizagem da leitura. In: MALUF, M. R. Metalinguagem e aquisição da escrita: contribuições da pesquisa para a prática de alfabetização. São Paulo: Casa do Psicólogo, 2003. p. 19-63.

GOUGH, P. B.; LARSON, K. C. A estrutura da consciência fonológica. In: CARDOSO-MARTINS, C. (Org.). Consciência fonológica \& alfabetização. Petrópolis, RJ: Vozes, 1995. p. 13-35

GRABE, W. Reading in a second Language: moving from Theory to Practice. Cambridge: Cambridge University Press, 2009.

KOCH, I. G. V.; CUNHA-LIMA, M. L. Do cognitivismo ao sociocognitivismo. In: MUSSALIM, F.; BENTES, A. C. (Org.). Introdução à linguística: fundamentos epistemológicos. 3. ed. São Paulo: Cortez, 2007. p. 251-300; 
KORKEAMÄKI, R.-L. What Can Be Learned About Reading Acquisition in the Finnish Language? In: LEONG, C. K.; JOSHI, R. M. (Ed.). Cross-Language Studies of Learning to Read and Spell. Phonologic and Orthografic Processing. Dordrecht/Boston/London: Kluwer Academic Publishers/ NATO Scientific Affairs, 1997. p. 331-359.

LAROCA, M. Manual de Morfologia do português. Campinas, SP: Pontes, Juiz de Fora, UFJF, 2005.

LEHTONEN, A.; BRYANT, P. Active players or just passive bystanders? The role of morphemes in spelling development in a transparent orthography. Applied Psycholinguistics. v. 26, n. 2, p. 137-155, 2005.

MAREC-BRETON, N.; GOMBERT, J. E. A dimensão morfológica nos principais modelos de aprendizagem da leitura. In: MALUF, M. R. (Org.). Psicologia Educacional: Questões Contemporâneas. São Paulo: Casa do Psicólogo, p. 105-121, 2004.

MELO, R. B. A relação entre consciência fonológica e aquisição da leitura e da escrita de jovens e adultos. Tese (Doutorado) Instituto de Psicologia, Universidade Federal do Rio de Janeiro, Rio de Janeiro, 2006.

MORAIS, J. Criar Leitores - Para professores e educadores. Barueri, SP: Manole, 2013.

MOTA, M. da. A consciência morfológica é um conceito unitário? In: MOTA, M. (Org.). Desenvolvimento metalinguístico: questões contemporâneas. São Paulo: Casa do Psicólogo, 2009. p. 41-54.

NUNES, T.; BRYANT, P. Improving Literacy by teaching Morphemes. London: Routledge, 2006.

PINTO, M. da G. L. C. Desenvolvimento e distúrbios da Linguagem. Porto: Porto Editora, 1994.

PINTO, M. da G. L. C. Saber viver a Linguagem: um desafio aos problemas de literacia. Porto: Porto Editora, 1998.

PRIMI, Ricardo. Inteligência: avanços nos modelos teóricos e nos instrumentos de medida. Aval. psicol., Porto Alegre, v. 2, n. 1, p. 67-77, jun. 2003. Disponível em <http://pepsic. bvsalud.org/scielo.php?script=sci_arttext\&pid $=$ S 1677 04712003000100008\&lng=pt\&nrm=iso $>$. Acesso em 04 set. 2017.

QUADROS, R. O paradigma gerativista e a aquisição da linguagem. In: FINGER, I.; QUADROS, R. (Org.). Teorias da aquisição da linguagem. Florianópolis: Editora da UFSC, 2008.

SANTOS, M. J. dos; MALUF, M. R. Consciência fonológica e linguagem escrita: efeitos de um programa de intervenção. In: MALUF, M. R. (Org.). Psicologia Educacional: questões contemporâneas. São Paulo: Casa do Psicólogo, 2004 p. 91-103,

SAUSSURE, F. de. Curso de Linguística Geral. 29. ed. São Paulo: Cultrix, 2008.

SClIAR-CABRAL, L. Princípios do Sistema Alfabético do Português do Brasil. São Paulo: Contexto, 2003a.

SCLIAR-CABRAL, L. Guia Prático de Alfabetização baseado em Princípios do Sistema Alfabético do Português do Brasil. São Paulo: Contexto, 2003 b.

SILVA, M. B. da. Leitura, ortografia e fonologia. 2. ed. São Paulo: Ática, 1993.

SILVA, M. C. de S.; KOCH, I. Linguística aplicada ao português: morfologia. São Paulo: Cortez, 1999.

SNOWLING, M.; STACKHOUSE, J. Dislexia, fala $e$ linguagem: um manual do profissional. Porto Alegre: Artes Médicas, 2004.

VELOSO, J. Da Investigação às Práticas. Estudos de Natureza Educacional, Escola Sup. de Educação de Lisboa, Centro Interdisciplinar de Estudos Educacionais, v. VI, p. 49-69, 2005.

Recebido: 30/09/2017

Aprovado: 10/12/2017

Contato:

Onici Claro Flôres < oflores@unisc.br> 